\title{
Should we avoid heparin based anticoagulants in "COVID-19 infection-vaccination related thrombosis"? Insights from the HIT like syndrome observed with infected cases.
}

Antoine AbdelMassih ( $\square$ antoine.abdelmassih@kasralainy.edu.eg )

Cairo University

Rafeef Hozaien

Cairo University

Meryam El Shershaby

Cairo University

Aya Kamel

Cairo University

Habiba-Allah Ismail

Cairo University

Raghda Fouda

Cairo University

Systematic Review

Keywords: Heparin induced thrombocytopenia, Anti-platelet factor 4 antibodies, ChAdOx vaccine

Posted Date: April 5th, 2021

DOI: https://doi.org/10.21203/rs.3.rs-393180/v1

License: (c) (i) This work is licensed under a Creative Commons Attribution 4.0 International License.

Read Full License 


\section{Abstract}

Background: Recent reports of the prothrombotic states announced in the recipients of the ChAdOx vaccine, similar to HIT sounded alarm bells internationally.

The sole outcome parameter of this systematic review was to detect similar cases of Prothrombotic state in COVID-19 infected patients

Methodology: Embase, Medline and the Cochrane Central Register were used to search for specic keywords such as "COVID-19" OR "SARS-CoV-2" AND "Heparin induced thrombocytopenia" for relevant publications up to $1^{\text {st }}$ of April 2021. The systematic review was performed using PRISMA protocol.

Results: Nine cases reports/series have been identified including 18 cases, venous thrombosis was the commonest type of observed thrombosis accounting for $72 \%$ of cases, the mean age of cases was $57 \pm 4$.

Conclusion: Similar episodes of HIT were detailed in several case reports of COVID patients. This suggests a common pathogenesis and warrants a screening of all COVID-19 patients presenting with thrombo-embolism using anti-PF4 antibodies and using non heparin based anticoagulants for their management.

\section{Background}

Currently, over 150 coronavirus vaccines are under development. In an attempt to stop the ongoing pandemic, numerous countries have issued emergency use authorization for many of those vaccines. (1) This hectic vaccine rollout means that not enough is known about their short and long-term consequences. In March of this year, reports broke out of strokes and prothrombotic states in ChAdOx vaccine recipients. The use of this vaccine was subsequently suspended in several European countries.

The European Medicines Agency (EMA) stated concern for the safety of the ChAdOx vaccine. However, Greinacher and colleagues showed (in a preprint) the serologic profile of patients who developed this unusual set of symptoms after the ChAdOx vaccine. They concluded that the prothrombotic state in these patients is similar to Heparin-induced thrombocytopenia (HIT). All nine patients showed positive antiplatelet factor 4 antibodies (anti-PF4), frequently seen in heparin recipients. None of these patients were on heparin before getting vaccinated. This implies that the ChAdOx vaccine can potentially induce such autoantibodies.(3)

The sole outcome parameter of this study was to review similar cases of Prothrombotic state associated with COVID-19 infection not vaccination.

\section{Methodology}


Embase, Medline and the Cochrane Central Register were used to search for specic keywords such as "COVID-19" OR "SARS-CoV-2" AND "Heparin induced thrombocytopenia" for relevant publications up to $1^{\text {st }}$ of April 2021. The systematic review was performed using PRISMA protocol.

Study Selection criteria Population:

No specic age group or sex

Intervention: COVID-19

Comparison: No comparison has been a purpose of the study

Outcome: Heparin induced thrombocytopenia

Observational epidemiological studies and case reports addressing inclusion criteria were included

\section{Results}

Several reports of HIT were reported (a total of 9 reports/series including 18 cases) before the current vaccine rollout; these were reviewed and summarized in table 1(4-12). All the reports incriminated heparin in the development of the observed prothrombotic state. These patients received heparin due to one of three reasons:

-Initial presentation with thrombosis

-Increased risk of thrombo-embolism development due to an underlying medical condition e.g. atrial fibrillation

-Extra membrane corporeal oxygenation

\section{Discussion}

+ls this an old, misinterpreted feature of Coronaviridae or is it a brand new feature?

A rise in similar reports following ChAdOx vaccination indicates that heparin might not be the cause of this HIT-like syndrome after all. Instead, SARS-CoV-2 could induce an autoantibody profile similar to that of HIT.

Also the pattern of observed thrombotic events is mainly venous, thus mimicking that observed in recipients of ChAdOx vaccination.

\section{+Diagnostic and therapeutic implications:}

These findings necessitate an update to laboratory testing and treatment of COVID-19 patients presenting with thrombosis, through the following: 


\section{-Routine anti-PF4 testing.}

The high prevalence of anti-PF4 in COVID-19 patients previously diagnosed with HIT (as mentioned in table 1) warrants screening of this antibody profile in COVID-19 infected patients presenting with thrombotic events as well as in recipients of ChAdOx vaccination.

\section{-Alternative anti-coagulants.}

Currently, three non-heparin anticoagulants, namely Danaproid, Lepirudin, and Argatroban, are used in HIT as alternative anticoagulants; this is because they do not cross-react with HIT antibodies. Low molecular weight heparin (LMWH) similarly is not to be used in COVID-19 patients and ChAdOx vaccinated individuals because of its cross-reactivity with PF4 autoantibodies. Warfarin, besides, is discouraged in HIT due to a paradoxical increase in the thrombotic tendency.

High-dose intravenous immunoglobulins are one of the most important and established therapies for HIT.

A final therapeutic approach of importance is using Hep-like molecules to disrupt the PF4-GAG complexes. This has been considered in the treatment of HIT and could be used as a treatment for the prothrombotic state in COVID-19 patients and ChAdOx -vaccinated individuals.(13)

Figure 1 outlines the diagnostic and therapeutic implications suggested above

\section{Conclusion}

Increasing evidence suggests that SARS-CoV-2 is an independent risk factor in the development of PF4 autoantibodies regardless of prior heparin therapy. The reports encountered after ChAdOx vaccination and earlier reports after infection provide strong evidence for such a hypothesis. This information warrants clinicians to screen such autoantibodies in any COVID-19 patient and ChAdOx vaccinated individuals presenting with a thrombotic event. It may also lead to changes in the anti-coagulant regimens used for such patients and the use of new treatments such as immunoglobulins and Hep-like molecules that can disrupt PF4-GAG complexes. In view of the available data, avoidance of heparinbased anticoagulants in COVID-19 patients and vaccinated individuals should be warranted. It also remains unclear, why such Prothrombotic state has been observed solely with COVID-19 infection, and with ChAdOx vaccine and not with the other available vaccines. This mandates a close follow up of recipients of other available COVID-19 vaccines to detect if similar Prothrombotic events would develop or not.

\section{Declarations}

\section{Conflict of interest:}

None 


\section{References}

1. Guerstein S, Romeo-Aznar V, Dekel M, Miron O, Davidovitch N, Puzis R, Pilosof S. Optimal strategies for combining vaccine prioritization and social distancing to reduce hospitalizations and mitigate COVID19 progression. medRxiv. 2020.

2. Sweden joins Germany, France, and 15 other countries in suspending AstraZeneca's vaccine over possible side effects [Internet]. Available from: https://www.businessinsider.com/astrazeneca-covidvaccine-countries-suspend-denmark-thailand-batch-blood-clots-2021-3

3. Greinacher A, Thiele T, Warkentin TE, Weisser K. A Prothrombotic Thrombocytopenic Disorder Resembling Heparin-Induced Thrombocytopenia Following Coronavirus-19 Vaccination. :1-8.

4. Madala S, Krzyzak M, Dehghani S. Is COVID-19 an Independent Risk Factor for Heparin-Induced Thrombocytopenia? Cureus. 2021;13(2):1-8.

5. Kewan T, Covut F, Daw H, Haddad A. Heparin-Induced Thrombocytopenia in a Patient With Coronavirus Disease-19. Am J Ther [Internet]. 2020 Dec 29;Publish Ah. Available from: https://journals.Iww.com/10.1097/MJT.0000000000001282

6. Lingamaneni P, Gonakoti S, Moturi K, Vohra I, Zia M. Heparin-Induced Thrombocytopenia in COVID19. J Investig Med High Impact Case Reports. 2020;8:4-7.

7. Sartori M, Cosmi B. Heparin-induced thrombocytopenia and COVID-19. Hematol Rep [Internet]. 2021 Mar 12;13(1). Available from: https://www.pagepress.org/journals/index.php/hr/article/view/8857

8. Bidar F, Hékimian G, Martin-Toutain I, Lebreton G, Combes A, Frère C. Heparin-induced thrombocytopenia in COVID-19 patients with severe acute respiratory distress syndrome requiring extracorporeal membrane oxygenation: two case reports. J Artif Organs [Internet]. 2020 Aug 12; Available from: http://link.springer.com/10.1007/s10047-020-01203-x

9. Ogawa Y, Nagata T, Akiyama T, Nishida K, Kumasawa J, Kohno M, Kohata H, Gohma I. Argatroban therapy for heparin-induced thrombocytopenia in a patient with coronavirus disease 2019. J Thromb Thrombolysis [Internet]. 2020 Nov 11;50(4):1012-4. Available from:

http://link.springer.com/10.1007/s11239-020-02248-8

10. Daviet F, Guervilly C, Baldesi O, Bernard-Guervilly F, Pilarczyk E, Genin A, Lefebvre L, Forel JM, Papazian L, Camoin-Jau L. Heparin-induced thrombocytopenia in severe COVID-19. Circulation. 2020;142(19):1875-7.

11. Lozano R FM. Incidence of heparin-induced thrombocytopenia in patients with 2019 coronavirus disease. Med Clin (Barc).

12. Phan XT, Nguyen TH, Tran TT, Huynh THT, Hoang THT, Nguyen VC V., Pham TNT. Suspected heparininduced thrombocytopenia in a COVID-19 patient on extracorporeal membrane oxygenation support: a case report. Thromb J. 2020;18(1):1-5.

13. Alkindi S, Smith OP, Enright H. Successful Use of Alternative Anticoagulants in the Management of Heparin-induced Thrombocytopenia with Thrombotic Complications: Report of 5 cases and review of 
literature. Sultan Qaboos Univ Med J [Internet]. 2011 Aug;11(3):391-8. Available from: http://www.ncbi.nlm.nih.gov/pubmed/22087382

\section{Tables}

Table 1: Summary of COVID-19 related cases of Heparin induced thrombocytopenia 


\begin{tabular}{|c|c|c|c|}
\hline Authors & Country & Age & Type of prothrombotic state \\
\hline Madala et al (4) & USA & 65 & $\begin{array}{l}\text { Lacunar infarct in basal ganglia and right sided } \\
\text { hemiplegia }\end{array}$ \\
\hline Kewan et al (5) & USA & 56 & DVT \\
\hline $\begin{array}{l}\text { Lingamaneni et al } \\
\text { (6) }\end{array}$ & USA & 63 & DVT \\
\hline Sartori et al (7) & Italy & 78 & DVT \\
\hline \multirow[t]{2}{*}{ Bidar et al (8) } & \multirow[t]{2}{*}{ France } & 62 & Pulmonary embolism \\
\hline & & 38 & Deteriorating oxygenation \\
\hline Ogawa et al (9) & Japan & 37 & DVT, massive pulmonary thromboembolism \\
\hline \multirow[t]{7}{*}{ Daviet et al (10) } & \multirow[t]{7}{*}{ France } & 46 & DVT \\
\hline & & 50 & Intracardiac thrombosis \\
\hline & & 43 & DVT \\
\hline & & 63 & Stroke \\
\hline & & 59 & DVT \\
\hline & & 57 & \multirow[t]{2}{*}{ None } \\
\hline & & 69 & \\
\hline Phan et al (12) & China & 43 & $\begin{array}{l}\text { DVT/Pulmonary micro-thrombi, deteriorating } \\
\text { oxygenation }\end{array}$ \\
\hline \multirow{3}{*}{$\begin{array}{l}\text { Lozano and } \\
\text { Franco (11) }\end{array}$} & \multirow[t]{3}{*}{ Spain } & 45 & \multirow[t]{3}{*}{ None } \\
\hline & & 71 & \\
\hline & & 90 & \\
\hline \multirow[t]{2}{*}{ Summary } & & \multirow{2}{*}{$\begin{array}{l}\text { Total of } 18 \\
\text { cases }\end{array}$} & 13 presented with thrombotic events ( $72 \%)$ \\
\hline & & & $\begin{array}{l}\text { DVT/pulmonary embolism: commonest } \\
\text { prothrombotic event ( } 9 \text { cases } / 61 \%)\end{array}$ \\
\hline
\end{tabular}

\section{Figures}




\section{Any case presenting with COVID-19 \\ ainfection or vaccination assocaited \\ thrombosis}

Test for anti PF4 antibodies

Start non heparin based

anticoagulants until results of antibody testing are availaible

\section{Figure 1}

Title: Suggested management of Prothrombotic event associated with COVID-19 infection or vaccination Abbreviations: PF4: Platelet Factor 4 